\title{
Supraseasonal drought in an Alpine river: effects on benthic primary production and diatom community
}

\author{
Elisa Falasco, ${ }^{1,23^{*}}$ Alberto Doretto, ${ }^{1,3}$ Stefano Fenoglio, ${ }^{2,3}$ Elena Piano, ${ }^{1,2,3}$ Francesca Bona ${ }^{2,3}$ \\ ${ }^{1}$ Department of Sciences and Technological Innovation, University of Piemonte Orientale "Amedeo Avogadro", Viale Teresa Michel \\ 25, 15121 Alessandria; ${ }^{2}$ Department of Life Sciences and Systems Biology, University of Turin, Via Accademia Albertina 13, 10123 \\ Turin; ${ }^{3}$ Alpine Stream Research Center (ALPSTREAM), 12030 Ostana, Italy
}

\begin{abstract}
Over the last decades, the ongoing global climate change, combined with consequent increasing water demand for human needs, is causing recurrent droughts in previously perennial streams. These phenomena have been dramatically increasing their extent, with significant repercussions on the entire food web. Consequences of water scarcity are particularly remarkable in mountain streams, where the frequency of droughts is increasing at a rate that does not allow species to adapt. In the present research, we monitored benthic diatom communities within an intermittent Alpine river (Pellice River; North-Western Italy) during the three key phases of its hydrological cycle: i) stable flow ii) lentification iii) rewetting of the riverbed after a supraseasonal drought lasting five months. We tested the response of diatom communities in terms of compositional, structural and functional metrics (primary production, species composition, ecological guilds, life forms and eco-morphological groups) hypothesising both taxonomic and functional changes during the different steps of this hydrological cycle. Significant changes in benthic chlorophyll $a$ occurred in the three hydrological phases. In particular, the relative proportion of the chlorophyll $a$ of the three main autotrophic groups inhabiting the periphyton (namely diatoms, cyanobacteria and green algae) resulted as a reliable metric for the evaluation of the hydrological disturbance. Diatom chlorophyll $a$ significantly decreased during both lentification and drought. The three phases were significantly characterized by different species and functional groups. During the stable flow the low profile (i.e., species of short stature, adapted to high current velocities and low nutrients concentrations) was the most representative guild and Achnanthidium pyrenaicum was the most abundant species; this phase was also characterized by the presence of stalked taxa. We observed a significant decrease of high profile species (i.e., species of tall stature, adapted to high nutrients concentrations and low current velocities) during the lentification phase, which was characterized by taxa belonging to the genera Navicula, Nitzschia and Ulnaria. During the rewetting, small and medium sized high profile diatoms as well as motile ones (i.e., fast moving species) characterized the assemblages. Our results showed that the complete recovery of diatom communities took at least 70 days after water return. The rapid and widespread extension of droughts in the Alpine area will have severe consequences on the river biota, also favouring the spread of invasive taxa. For this reason, outlining patterns of diatom response to droughts and detecting reliable metrics for the evaluation of this specific impact is very urgent and important.
\end{abstract}

\section{INTRODUCTION}

Hydrological disturbance in rivers created by extreme events, like floods and droughts, affects biological communities in different ways, such as inducing productivity

Corresponding author: elisa.falasco@unito.it

Key words: Bacillariophyceae; functional metrics; hydrological cycle; lentification; resilience.

Edited by: Diego Fontaneto, CNR-IRSA Water Research Institute, Verbania, Italy.

Received: 30 July 2019.

Accepted: 12 December 2019.

This work is licensed under a Creative Commons Attribution NonCommercial 4.0 License (CC BY-NC 4.0).

${ }^{\circ}$ Copyright: the Author(s), 2020

Licensee PAGEPress, Italy

J. Limnol., 2020; 79(2): 97-110

DOI: 10.4081/jlimnol.2020.1933 shifts, increasing or interrupting the three-dimensional connectivity of the stretches and altering the physical and chemical conditions of the river (Van Looy et al., 2019). In particular, drought events in Alpine rivers have been dramatically increasing during the last decades due to the combined effect of global climate change and the consequent increasing water demand for human purposes. Droughts are becoming particularly intense and widespread phenomena, which leave several kilometres of riverbeds completely dry for many months, even after summer (Fenoglio et al., 2010; Piano et al., 2019a). These kind of events have been defined by Lake (2003) as "supraseasonal droughts": unpredictable and aseasonal droughts caused by a decrease of the precipitations and water availability. Over the last years, supraseasonal droughts occurring in the Cottian Alps (Northwestern Italy) have been receiving an impressive eco among valley inhabitants and national media. For instance, in 2017 dryness was particularly strong and on September, the spring of the most important and longest Italian river, the Po, got dry. This triggered a cascade of events, which moved the interest of both local and national media on this phenomenon, with several articles published in the newspapers and reports broadcast in the TV. Beside the consequences on 
the river biota, the hydrological crisis of 2017 led to heavy damages to the agriculture, with a loss estimation of 185.4 million euros, only in the Piedmont region.

Drought events have been highlighted to affect the entire river biota, with final consequences on the whole food web throughout an increase of the competition and predation rate, and changes in the nature of food resources (Fenoglio et al., 2010). The effects of droughts on the Alpine river communities have been recently explored at different levels, from fish (Fenoglio et al., 2010), to benthic macroinvertebrates (Fenoglio et al., 2007; Doretto et al., 2018; Piano et al., 2019b) and unicellular organisms inhabiting the biofilm (Falasco et al., 2018a). For instance, in their recent work, Piano et al. (2019b) confirmed that drought prevents the development of thick and mature periphyton, it promotes heterotrophy and alters the fatty acid composition of the biofilm. In that work, it was observed that all these alterations led to a reduced grazing efficiency of the macroinvertebrate scrapers and, as a consequence, to a reduction of their ecological niche. Within periphyton communities, autotrophic groups are the most affected by drought conditions compared to bacteria (Timoner $e t$ al., 2014), with proportional effects according to the duration of the dry period (Acuña et al., 2015). Droughts have immediate effects on the autotrophic processes, which can be recorded through several ecological metrics, such as chlorophyll $a$, which shows a significant disturbance-response relationship (Piano et al., 2017). Among benthic primary producers, diatoms showed lower resistance to dry conditions compared to cyanobacteria and green algae (Acuña et al., 2015; Piano et al., 2015; 2017), due to their low ability to develop desiccation-tolerance mechanisms, contrarily to the other two groups. However, exceptions occur. Indeed, some diatom species such as those belonging to the genera Diadesmis, Hantzschia or Nupela, are naturally adapted to colonise also aerial habitats (see Falasco et al., 2015 for an example). Despite this, in general diatoms can survive to droughts mainly exploiting refugia, such as residual pools, leaf packs and dry biofilm (McQuoid and Hobson, 1996; Robson and Matthews, 2004; Souffreau et al., 2013). Notwithstanding their ability to cope with desiccation remains low, diatoms demonstrated to have a greater resilience capacity than other autotrophic groups (Stanley et al., 2004; Acuña et al., 2015).

In this context, Van Looy et al. (2019) explored three mechanisms promoting community resilience in rivers affected by hydrological disturbance, related to resources, recruitment and refugia. In particular: i) temporal resource variation results in resource pulses, which in turn causes internal reorganization of communities based on intraand interspecific interactions; ii) the spatial organization of habitat patches favours or disfavours colonization processes depending on habitat connectivity/fragmentation, species' dispersal ability and size of species pool within the area; iii) environmental heterogeneity guarantees the presence of refugia where species can survive during extreme events. These three resilience mechanisms are intrinsically linked to the composition in species during the pre-drought event and/or to the composition of the assemblages colonizing the permanent stretches, which serve as source during the recolonization process. For instance, in a previous study carried out in three Mediterranean streams, we pointed out that communities composed by high percentages of endangered diatoms were less resilient than those composed of generalists and ubiquitous taxa (Falasco et al., 2018b). Only in this second case, the communities were able to completely recover just one month after the disturbance event, while threatened species slowed the periphyton speed recovery, which did not reach the pre-drought state even after 3 months. The resilience capacity is also strictly dependent on the functional traits of species composing source communities. In this context, recent results obtained by Soininen et al. (2016) underlined the importance of considering guild composition in tracking and assessing environmental gradients. In particular, the authors observed that diatom species composition better explains geographical distribution, with biogeographical patterns similar to those of larger organisms, while ecological guilds better describe the environmental gradients, partially reconfirming the finding of Passy (2007). To further confirm this, BBéres et al. (2019) found a significant decrease of the functional richness in intermittent sections compared to permanent ones.

In the present research, we monitored three key phases of the hydrological cycle of an Alpine intermittent river, namely stable flow, lentification (see Sabater, 2008 and Falasco et al., 2018a for a definition) and rewetting, in order to identify which metrics referred to diatom communities best respond to each of them. In all these three phases, we examined the response of diatom community by analyzing not only the taxonomic composition, but also functional metrics: primary production, ecological guilds, life forms and eco-morphological groups. The overall aim of this paper is to strengthen our knowledge on the response of benthic diatom communities to the physical stress created by the alteration of the hydrological cycle in the Alpine rivers. Specifically, we aimed at: i) exploring the modes, timing and patterns of periphyton recovery after a supraseasonal drought event; ii) analyzing changes within the diatom community in terms of species composition during the different phases of the hydrological cycle; iii) identifying functional metrics within the diatom communities, that can provide insights into the hydrological alterations of recently intermittent streams. 


\section{METHODS}

\section{Study area}

The present study was carried out in the Pellice River (Northwest Italy), which is one of the most important tributaries of the Po River within the Southwest Alps. Notwithstanding the mean annual discharge $\left(4.3 \mathrm{~m}^{3} \mathrm{~s}^{-1}\right.$ at the studied sections; http://www.provincia.torino.gov.it/natura/ file-storage/download/linee_indirizzo_pesca.pdf) is similar to other permanent Alpine watercourses, this river is affected by recurrent supraseasonal droughts since 2011. In particular, the stretch located about $30 \mathrm{~km}$ from its source has been affected by an exceptional supraseasonal drought in 2017. Indeed, from August 2017 to the beginning of January 2018 (ca. 130 days) about $12 \mathrm{~km}$ of the Pellice River, from Bricherasio (32T 0366616 UTM 4964138) to Villafranca Piemonte (32T 0378214 UTM 4963515) were completely dry. Maps illustrating the cumulative precipitation amount $(\mathrm{mm})$ in the studied area, from January 2017 to March 2018, are shown in Doretto et al. (2020). In order to investigate the effect of the lentification process preceding the drought and the following recolonization phase, we monitored the first part of this stretch (hereafter downstream site, DW), together with a section with permanent flow located about $3 \mathrm{~km}$ upstream as a reference site (hereafter upstream site, UP). The surrounding land use of both sites is similar and is mainly characterized by orchards and vineyards and, in part, by riparian forests (see Falasco et al., 2018a for further details on sampling site location and percentages of land use in the studied area). According to the water Framework Directive 2000/60 the ecological status of these sites is "good" and their diatom flora is representative of the Western-Alps (Falasco et al., 2013).

In order to monitor the pre-drought phase, in 2017 we performed monthly sampling sessions (see Tab. 1 for dates and codes), from early spring (March) to summer (August). In particular: (1) sampling sessions from March to June 2017 were considered as representative of the "stable flow" (number of diatom samples analysed $n=8$ ); (2) July and August 2017 campaigns as representative of the "lentification" process (number of diatom samples analysed $n=4)$. Then, in order to monitor the "rewetting" phase (3), we performed frequent sampling sessions especially at the DW site, after the water flow return, which occurred on $9^{\text {th }}$ January 2018 (total number of diatom samples collected $n=39$; analysed $n=27$ ). During this phase, 36 stony artificial bare substrates (i.e., squared tiles expressly made of local rocks; dimensions $9 * 9 \mathrm{~cm}$ ) were interspersed on the streambed within a $10 \mathrm{~m}$ stretch at the downstream site. We chose to position our tiles in a lateral branch of the river, in order to prevent their rolling and/or lost. The use of artificial substrates allowed avoiding potential confounding effects on the recolonization pattern due to the different structure of natural cobbles (i.e. shape, roughness, presence of crevices...) and to the possible presence of resistance forms surviving during the drought. The monitoring of this last phase allowed us to detect the temporal pattern of the recolonization process of the diatom communities.

\section{Physical and chemical parameters}

On each sampling occasion, we measured the most important physical and chemical water parameters. In particular, we recorded water temperature (Temp), dissolved oxygen (DO), $\mathrm{pH}$ and conductivity (Cond) by means of a multiparametric probe (Hydrolab mod. Quanta). Current velocity (Vel) was measured by means of a current meter (Mod RHCM Idromar) placed at $0.05 \mathrm{~m}$ from the bottom of the riverbed, while water depth was measured by means of a meter tape. Water samples were collected for laboratory analyses of the soluble reactive phosphorous (SRP; ac-

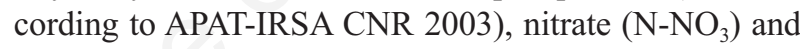
ammonium nitrogen $\left(\mathrm{N}-\mathrm{NH}_{3}\right)$, performed by means of a LASA100 spectrophotometer with specific analysis kits. In detail, SRP was measured throughout the molybdenum blue colorimetric analysis with ascorbic acid as reducing agent. $\mathrm{N}^{-\mathrm{NO}_{3}}$ was estimated throughout the reaction between sulphuric and phosphoric acids with 2,6-dimethylphenol to form 4-nitro-2,6-dimethylphenol. For $\mathrm{N}-\mathrm{NH}_{3}$ ammonium ions reacted at $\mathrm{pH} 12.6$ with hypochlorite ions and salicylate ions in the presence of sodium nitroprusside as a catalyst, to form indophenol blue.

\section{Chlorophyll-a}

During each sampling campaign, we measured the amount of benthic chlorophyll $a$ by means of the BenthoTorch, developed by BBE Moldaenke GmbH (Schwentinental, Germany). BenthoTorch is a fluorometric probe emitting light pulses at three different wavelengths (470, 525 and $610 \mathrm{~nm}$ ), recording the response of diatoms, cyanobacteria and green algae at $690 \mathrm{~nm}$ wavelength (Kahlert and McKie 2014). After each measurement we were able to obtain: i) the amount of benthic chlorophyll $a$ (hereafter chla) of the three main autotrophic groups composing the biofilm (i.e., diatoms, cyanobacteria and green algae); ii) the total benthic chlorophyll $a$ of the periphyton (hereafter total chla) obtained by summing up the diatom, cyanobacteria and green algae chla values; iii) the relative contribution of each autotrophic group (as percentage) to the total chla (diatom chla / total chla; cyanobacteria chla / total chla; green algae chla / total chla). During each sampling campaign and at each sampling station, we collected three substrates from the riverbed and we performed three measurements of chla on each surface ( 3 measurements $X 3$ substrates $=9$ chla measures for each date). During the rewetting phase, chla 
was measured on the surface of natural cobbles at UP site, while on the artificial substrates at DW.

\section{Diatom community}

In order to analyse the diatom community, during the stable flow and the lentification phases, we collected diatom samples by carefully brushing three natural cobbles located along a linear transect and the samples were pooled together. The same procedure was followed at UP site during the rewetting phase. During this phase, at DW site, we collected three replicates of periphyton by brushing three different artificial substrates. These samples were kept and analysed separately one from the other, for community analysis purposes (in total 27 samples $=3$ tiles X 9 sam- pling occasions). We decided to sample cobbles in the UP section to be more realistic as possible when describing the species that possibly drift downstream during the recolonization phase. Indeed, even though bare tiles have been recognized as a realistic representation of natural cobbles, we wanted to be sure not to exclude any species (present in the UP site, but likely slower to colonize bare substrates) participating in the recolonization phase. On the contrary, we chose to use tiles at DW and kept the 3 replicates separated for the community analysis mainly to: i) exclude the presence of resting forms which could be present on the natural substrate (and would have produced confounding effects during the results interpretation); ii) to comply with the requirements of the PRC analysis (that need at least 3 replicates for each tested treatment).

Tab. 1. Physical and chemical parameters detected during the survey.

\begin{tabular}{|c|c|c|c|c|c|c|c|c|c|c|c|c|c|c|}
\hline & Site & Date & Code & $\begin{array}{l}\text { Days } \\
\text { from } \\
\text { water } \\
\text { return }\end{array}$ & $\begin{array}{c}\text { Cond } \\
\left(\mu \mathrm{cm}^{-1}\right)\end{array}$ & $\begin{array}{l}\text { DO } \\
(\%)\end{array}$ & $\begin{array}{c}\text { DO } \\
\left(\mathrm{mg} \mathrm{L}^{-1}\right)\end{array}$ & $\mathrm{pH}$ & $\begin{array}{c}\text { Temp } \\
\left({ }^{\circ} \mathrm{C}\right)\end{array}$ & $\begin{array}{c}\text { SRP } \\
\left(\mathrm{mg} \mathrm{L}^{-1}\right)\end{array}$ & $\begin{array}{c}\mathrm{N}-\mathrm{NO} 3 \\
\left.(\mathrm{mg} \mathrm{L})^{-1}\right)\end{array}$ & $\begin{array}{c}\mathrm{N}-\mathrm{NH3} \\
\left(\mathrm{mg} \mathrm{L}^{-1}\right)\end{array}$ & $\begin{array}{l}\text { Vel }\left(\mathrm{m} \mathrm{s}^{-1}\right) \\
(\text { mean } \pm \text { sd) }\end{array}$ & $\begin{array}{r}\text { Depth }(\mathrm{cm}) \\
(\text { mean } \pm \text { sd) }\end{array}$ \\
\hline \multirow[t]{8}{*}{ Stable flow } & UP & $22 / 03 / 2017$ & S3 & & 121 & 92.0 & 9.70 & 7.07 & 9.06 & 0.01 & 1.000 & 0.116 & $0.38 \pm 0.15$ & $31.0 \pm 1.0$ \\
\hline & DW & $22 / 03 / 2017$ & S3 & & 132 & 113 & 13.1 & 7.00 & 8.88 & 0.019 & 0.975 & 0.159 & $0.52 \pm 0.23$ & $15.7 \pm 3.5$ \\
\hline & UP & $19 / 04 / 2017$ & S4 & & 116 & 101 & 12.2 & 7.98 & 7.63 & 0.022 & 0.980 & 0.170 & $0.71 \pm 0.26$ & $54.3 \pm 3.8$ \\
\hline & DW & $19 / 04 / 2017$ & S4 & & 117 & 86.9 & 10.7 & 7.69 & 6.79 & 0.011 & 0.800 & 0.204 & $0.56 \pm 0.05$ & $33.3 \pm 7.3$ \\
\hline & UP & $24 / 05 / 2017$ & S5 & & 114 & 91.7 & 9.91 & 7.52 & 12.2 & 0.000 & 0.785 & 0.017 & $0.69 \pm 0.21$ & $50.3 \pm 2.5$ \\
\hline & DW & $24 / 05 / 2017$ & S5 & & 120 & 101 & 11.1 & 7.39 & 11.3 & 0.000 & 0.267 & 0.011 & $1.1 \pm 0.11$ & $24.7 \pm 4.6$ \\
\hline & UP & $23 / 06 / 2017$ & S6 & & 144 & 90.8 & 8.81 & 7.75 & 16.4 & 0.000 & 0.676 & 0.026 & $0.39 \pm 0.25$ & $41.7 \pm 8.5$ \\
\hline & DW & $23 / 06 / 2017$ & S6 & & 145 & 94.5 & 9.42 & 7.47 & 16.7 & 0.000 & 0.718 & 0.010 & $0.27 \pm 0.20$ & $25.3 \pm 9.5$ \\
\hline \multirow[t]{4}{*}{ Lentification } & UP & $26 / 07 / 2017$ & L7 & & 179 & 101 & 9.64 & 8.13 & 17.7 & 0.002 & 0.847 & 0.043 & $0.38 \pm 0.22$ & $32.3 \pm 15.0$ \\
\hline & DW & $26 / 07 / 2017$ & L7 & & 170 & 108 & 9.75 & 8.79 & 20.1 & 0.013 & 0.475 & 0.039 & $0.40 \pm 0.37$ & $13.3 \pm 5.7$ \\
\hline & UP & $21 / 08 / 2017$ & L8 & & 188 & 65.0 & 5.83 & 8.47 & 20.6 & 0.009 & 1.050 & 0.052 & $0.20 \pm 0.11$ & $17.0 \pm 4.4$ \\
\hline & DW & $21 / 08 / 2017$ & L8 & & 199 & 59.0 & 5.72 & 7.67 & 17.4 & 0.016 & 0.626 & 0.054 & $0.03 \pm 0.03$ & $29.7 \pm 9.5$ \\
\hline \multicolumn{15}{|c|}{ Drought from the end of August 2017 to 9th January 2018 (about 130 days) } \\
\hline \multirow[t]{15}{*}{ Rewetting } & DW & $12 / 01 / 2018$ & RT1 & 3 & 139 & 94.7 & 11.9 & 7.30 & 5.50 & n.d. & n.d. & n.d. & $0.00 \pm 0.00$ & $9.0 \pm 4.0$ \\
\hline & DW & $16 / 01 / 2018$ & RT2 & 7 & 153 & 107 & 13.6 & 7.41 & 4.87 & 0.008 & 2.030 & 0.049 & $0.03 \pm 0.03$ & $19.3 \pm 5.0$ \\
\hline & DW & $19 / 01 / 2018$ & RT3 & 10 & 145 & 91.4 & 12.4 & 7.62 & 3.03 & 0.004 & 1.710 & 0.018 & n.d. & n.d. \\
\hline & UP & $23 / 01 / 2018$ & RT4 & 14 & 149 & 97.0 & 12.9 & 7.55 & 3.55 & 0.003 & 1.660 & 0.020 & $0.49 \pm 1.17$ & $19.7 \pm 8.4$ \\
\hline & DW & $23 / 01 / 2018$ & RT4 & 14 & 154 & 98.2 & 12.7 & 7.71 & 4.56 & 0.021 & 3.690 & 0.031 & $0.01 \pm 0.01$ & $17.0 \pm 3.5$ \\
\hline & DW & $30 / 01 / 2018$ & RT5 & 21 & 145 & 100 & 13.2 & 7.57 & 3.72 & 0.002 & 1.400 & 0.043 & $0.05 \pm 0.08$ & $19.3 \pm 1.5$ \\
\hline & DW & $01 / 02 / 2018$ & RT6 & 23 & 148 & 120 & 14.8 & 7.86 & 6.16 & 0.032 & 1.560 & 0.013 & $0.03 \pm 0.01$ & $20.7 \pm 3.5$ \\
\hline & DW & $06 / 02 / 2018$ & RT7 & 28 & 150 & 106 & 13.6 & 7.93 & 4.52 & 0.008 & 0.755 & 0.029 & $0.00 \pm 0.00$ & $14.3 \pm 2.8$ \\
\hline & DW & $09 / 02 / 2018$ & RT8 & 31 & 155 & 102 & 12.8 & 8.14 & 5.92 & 0.008 & 1.400 & 0.022 & $0.02 \pm 0.02$ & $12.3 \pm 1.2$ \\
\hline & UP & $16 / 02 / 2018$ & RT9 & 38 & 153 & 111 & 14.8 & 8.20 & 3.23 & 0.028 & 1.120 & 0.027 & $0.32 \pm 0.02$ & $16.7 \pm 5.0$ \\
\hline & DW & $16 / 02 / 2018$ & RT9 & 38 & 160 & 105 & 14.1 & 8.04 & 3.24 & 0.000 & 1.380 & 0.016 & $0.01 \pm 0.00$ & $15.3 \pm 2.1$ \\
\hline & DW & $23 / 02 / 2018$ & RT10 & 45 & 151 & 106 & 14.3 & 8.24 & 2.85 & 0.074 & 1.420 & 0.054 & $0.04 \pm 0.02$ & $20.3 \pm 2.1$ \\
\hline & DW & $09 / 03 / 2018$ & RT11 & 59 & 147 & 95.7 & 12.3 & 8.39 & 4.55 & 0.003 & 1.410 & 0.033 & $0.07 \pm 0.04$ & $20.3 \pm 1.5$ \\
\hline & UP & $22 / 03 / 2018$ & RT12 & 73 & 117 & 95.6 & 12.4 & 8.06 & 4.32 & 0.039 & 1.020 & 0.041 & $0.67 \pm 0.32$ & $30.3 \pm 9.1$ \\
\hline & $\overline{\mathrm{DW}}$ & $22 / 03 / 2018$ & RT12 & 73 & 122 & 93.4 & 11.7 & 8.38 & 5.71 & 0.020 & 1.380 & 0.019 & $0.06 \pm 0.03$ & $37.0 \pm 2.6$ \\
\hline
\end{tabular}

Cond, conductivity; DO, dissolved oxygen; Temp, water temperature; SRP, soluble reactive phosphorous; $N$-NO3, nitrates; $\mathrm{N}$-NH3, ammoniacal nitrogen; Vel, flow velocity; Depth, water depth; n.d., not detected. 
All the samples were preserved in ethanol and treated in laboratory, following the European standard procedure (European Committee for Standardization 2003). A cleaned suspension of diatoms was obtained by boiling samples with hydrogen peroxide (30\%) and $\mathrm{HCl}(1 \mathrm{~N})$. Slides for

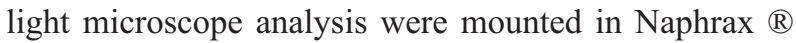
resin and analysed at $100 \mathrm{X}$ with immersion oil.

At least 400 valves per slide were identified according to the most common European diatom floras and monographies as well as recent taxonomic papers (see Falasco et al. 2016a for further details). The only exception was represented by DW diatom community at RT4: due to the low density of the individuals in the slide, we decided to identify only 100 valves to have a qualitative estimate of the species presence during the first days of the recovery. We are aware that data deriving from this analysis cannot be considered fully reliable, thus these results are discussed with caution in the following sections.

Recorded species were then classified into the following functional groups: (1) ecological guilds (low profile, high profile, motile and planktonic; according to Rimet and Bouchez, 2012); (2) growth forms (adnate, pad-attached, stalked, motile and tube-forming; according to Rimet and Bouchez, 2012); (3) eco-morphological forms (referring to B-Béres et al., 2016).

\section{Statistical analyses}

Differences in terms of physical and chemical parameters among the three phases of the hydrological cycle were tested using the analysis of the variance (ANOVA) followed by a Tukey's post-hoc test, by means of PAST 3.12 (Hammer et al., 2001). All the parameters were $\log (x+1)$ transformed before the analysis.

Then, we tested the temporal variability of the total benthic chla and that of the three algal groups (i.e., diatom, cyanobacteria, green algae) as well as their relative proportions during the three phases of the hydrological cycle at DW, via Generalized Additive Model (GAM) in R environment (R Core Team, 2018). Prior to perform statistical models, we carried out the data exploration and evaluated correlations (Pearson) among data in accordance with the protocol proposed by Zuur et al. (2010). Outliers were removed and highly correlated variables were excluded to avoid confounding effects and model overfitting (Zuur et $a l ., 2010)$. Data on the concentration of chlorophyll $a$ of diatom, cyanobacteria and total chlorophyll $a$ were $\log (\mathrm{x}+1)$ transformed and for these biological metrics a normal distribution was applied. On the contrary, for green algae chla and for all the relative proportions, models were fitted with a binomial distribution which is able to deal with both presence/absence data (Bernoulli distribution) and proportional data (strictly binomial distribution) as recommended in Zuur et al., 2009. The factor "time" was considered as a continuous variable by assigning a numerical value to each sam- pling campaign in relation to the drought: negative values were assigned to the pre-drought phases, while progressive positive values were assigned to the sampling campaigns of the rewetting phase. GAMs were performed with the "gam" function in the $m g c v$ R package (Wood and Wood, 2015).

Before analysing community data, we excluded from the biological database all those species identified only in one sample out of 42 and those species whose maximum relative abundance was $<1 \%$. We performed a Principal Coordinate Axes (PCoA) with Bray-Curtis as distance measure to visually inspect differences in community composition among samples taken in different phases of the hydrological cycle of the Pellice River. We then tested whether dissimilarity in taxa composition was significantly different among the three groups (i.e., stable flow, lentification and rewetting) through a PERMANOVA with 9999 random permutations. Both analyses were performed by means of the statistical software PAST 3.12 (Hammer et al., 2001). Due to the very low abundances detected and the scarce reliability of the community sampled at DW site during RT4, we excluded these samples from the PCoA analysis. Afterwards, we performed an Indicator Species Analysis (ISA) to highlight statistically significant species, representative of the three groups derived from the PCoA, with the function "multipatt" in the package indicspecies (De Caceres and Legendre, 2009) in the R statistical software (R Core Team, 2018). Differences in terms of ecological guilds, life forms and eco-morphological groups among the three phases of the hydrological cycle were tested using the analysis of the variance (ANOVA) followed by a Tukey's post-hoc test (PAST 3.12; Hammer et al., 2001). Finally, changes in the relative abundances of diatom species only during the rewetting phase were analysed with the Principal Response Curves (PRC, van den Brink et al., 2009) with the function "prc" of the package vegan (Oksanen et al., 2015) in the R statistical software (R Core Team, 2018). Significance was tested by means of a Monte Carlo test with 999 permutations. The PRC graph allows assessing the distance of communities observed in a treatment (i.e., DW) with a control community (i.e., UP) over time.

\section{RESULTS}

\section{Physical and chemical parameters}

The values of the main physical and chemical parameters measured during the surveys are shown in Tab. 1. We detected statistically significant differences among the three phases of the hydrological cycle (i.e., stable flow, lentification and rewetting) for most of the environmental parameters and for nitrates (Tab. 2). Conductivity was generally low (114-199 $\mu \mathrm{S} \mathrm{cm}^{-1}$ ) and we observed a significant increasing trend during the lentification phase, but fluctuating values during the rewetting. In particular, conductivity 
ranged from 139 to $160 \mu \mathrm{S} \mathrm{cm}^{-1}$ at the beginning of the rewetting, and decreased down to $122 \mu \mathrm{S} \mathrm{cm}^{-1}$ during campaign RT12. Dissolved oxygen was generally high during the whole experiment, with the exception of measures collected in July and August 2017, when lentification and water temperature were at their maximum (max water temperature $=20.6^{\circ} \mathrm{C}$ ). We did not detect statistically significant differences in terms of SRP and $\mathrm{N}_{-} \mathrm{NH}_{3}$ that were generally low during the whole survey. The highest levels of nitrates were detected during the rewetting phase and in particular at DW station. While the UP nitrate levels never exceeded 1.660 $\mathrm{mgL}^{-1}$, they reached a maximum value of 3.690 at DW site during January 2018. Thus, according to the Italian Water Legislation (D. Leg. 152/2006 and successive ones) the sites can be classified, at worst, as $\beta$-mesotrophic.

Positive correlations between time and dissolved oxygen, $\mathrm{pH}$ and nitrates, were revealed by the Pearson correlation test (Supplementary Material 1). Negative correlations were detected among time and temperature, flow velocity and depth (Supplementary Material 1). No significant relationship was found between time and conductivity, probably due to the slight fluctuations detected during the rewetting phase. Based on these results, we can argue that most of the environmental and chemical differences detected during the monitoring reflect in the best way the hydrological changes observed during the whole survey, and time represents a good proxy of the different phases of the hydrological cycle.

\section{Chlorophyll $a$}

The mean total chla was in line with the low trophic status of the river $\left(2.28 \mu \mathrm{g} \mathrm{cm}^{-2} \pm 2.93\right)$. During the first part of the survey (stable flow), we recorded similar values of total chla at both UP and DW sites. Afterwards, the lentification was characterized by a slight increase in the total productivity, especially at UP station, in accordance with the seasonal trend. During the rewetting, at DW station, we detected no algal activity during the first two sampling sessions (RT1 and RT2; see Tab. 1 for code explanation). At RT3, we recorded only the presence of green algae, with values ranging from 0.02 to $0.03 \mu \mathrm{g} \mathrm{cm}^{-2}$, while no diatoms or cyanobacteria were detected. Diatom presence was observed starting from RT4, even if with very low values (median value $0.05 \mu \mathrm{g} \mathrm{cm}^{-2}$ ). The total benthic productivity at DW showed a sharp increase one month after water return (RT7; median value $1.45 \mu \mathrm{g} \mathrm{cm}^{-2}$ ) and grew over the next 45 days, up to reach a peak at RT11 (median value $10.05 \mu \mathrm{g} \mathrm{cm}^{-2}$ ). Finally, it decreased from 10.05 to $4.60 \mu \mathrm{g} \mathrm{cm}^{-2}$ at RT12. Patterns of total chla, as well as chla of diatoms, cyanobacteria and green algae, over the time at DW stations were confirmed through GAMs (Tab. 3 and Fig. 1). The effect of time was statistically significant, except for green algae,

Tab. 2. Results of the analysis of the variance (ANOVA) performed to detect significant differences among the three different phases of the hydrological cycle and physical and chemical parameters. Significant results are shown in bold.

\begin{tabular}{|c|c|c|c|c|c|c|c|c|c|c|c|c|}
\hline \multicolumn{3}{|l|}{ ANOVA test } & $\begin{array}{c}\text { Cond } \\
\left(\mu \mathrm{S} \mathrm{cm} \mathrm{cm}^{-1}\right)\end{array}$ & $\begin{array}{l}\text { DO } \\
(\%)\end{array}$ & $\begin{array}{c}\text { DO } \\
\left(\mathrm{mg} \mathrm{L}^{-1}\right)\end{array}$ & $\mathrm{pH}$ & $\begin{array}{r}\text { Temp } \\
\left({ }^{\circ} \mathrm{C}\right)\end{array}$ & $\begin{array}{c}\text { SRP } \\
\left(\mathrm{mg} \mathrm{L}^{-1}\right)\end{array}$ & $\begin{array}{l}\mathrm{N}-\mathrm{NO} 3 \\
\left(\mathrm{mg} \mathrm{L}^{-1}\right)\end{array}$ & $\begin{array}{l}\mathrm{N}-\mathrm{NH3} \\
\left(\mathrm{mg} \mathrm{L}^{-1}\right)\end{array}$ & $\begin{array}{l}\text { Vel }\left(\mathrm{m} \mathrm{s}^{-1}\right) \\
(\text { mean } \pm \text { sd })\end{array}$ & $\begin{array}{r}\text { Depth }(\mathrm{cm}) \\
(\mathrm{mean} \pm \mathrm{sd})\end{array}$ \\
\hline \multirow{2}{*}{\multicolumn{2}{|c|}{$\begin{array}{l}\text { Hydrological disturbance } \\
\text { (GROUP } 1,2,3 \text { ) }\end{array}$}} & $\mathbf{F}$ & 22.7 & 4.792 & 19.01 & 4.290 & 19.63 & 8.286 & 8.775 & 2.023 & 24.35 & 13.54 \\
\hline & & $\mathbf{P}$ & 0.000 & 0.018 & 0.000 & 0.025 & 0.000 & 0.754 & 0.001 & 0.1552 & 0.000 & 0.000 \\
\hline \multirow[t]{3}{*}{ Tukey's post-hoc } & \multicolumn{2}{|c|}{ Stable $v s$ lentification } & 0.000 & 0.048 & 0.000 & 0.012 & 0.002 & 0.972 & 0.746 & 0.6403 & 0.000 & 0.005 \\
\hline & \multicolumn{2}{|c|}{ Stable $v s$ rewetting } & 0.031 & 0.743 & 0.18 & 0.384 & 0.034 & 0.883 & 0.023 & 0.2675 & 0.000 & 0.000 \\
\hline & \multicolumn{2}{|c|}{ Lentification $v s$ rewetting } & g $\quad \mathbf{0 . 0 0 0}$ & 0.014 & 0.000 & 0.199 & 0.000 & 0.763 & 0.004 & 0.7733 & 0.234 & 0.592 \\
\hline
\end{tabular}

Cond, conductivity; DO, dissolved oxygen; Temp, water temperature; SRP, soluble reactive phosphorous; $N$-NO3, nitrates; N-NH3, ammoniacal nitrogen; Vel, flow velocity; Depth, water depth

Tab. 3. Statistics of the GAMs for the chlorophyll $a$. Significant values are in bold.

\begin{tabular}{lccccc} 
& Estimate & edf & ref.df & F $0 \chi^{2}$ & P \\
Chla_tot & 0.667 & 3.785 & 3.973 & 27.04 & $<0.001$ \\
\hline Chla_D & 0.193 & 3.794 & 3.975 & 11.88 & $<0.001$ \\
\hline Chla_C & -3.027 & 3.467 & 3.821 & 10.20 & 0.052 \\
\hline Chla_G & 0.788 & 3.889 & 3.993 & 29.59 & $<0.001$ \\
\hline Chla_D/Chla_tot & 0.786 & 2.991 & 3.511 & 0.52 & 0.05 \\
\hline Chla_C/Chla_tot & -2.013 & 1 & 1 & 7.22 & 0.818 \\
\hline Chla_G/Chla_tot & -2.629 & 2.294 & 2.781 & $\mathbf{0 . 0 5}$
\end{tabular}

Chla tot, total chlorophyll a; Chla D, =diatom chlorophyll a; Chla C, cyanobacteria chlorophyll a; Chla G, green algae chlorophyll a; Chla D/Chla tot, relative proportion of diatoms (diatom chlorophyll a / total chlorophyll a); Chla_C/Chla_tot, relative proportion of cyanobacteria (cyanobacteria chlorophyll a / total chlorophyll a); Chla_G/Chla_tot, relative proportion of green algae (green algae chlorophyll a / total chlorophyll a). 
which showed a near significant effect $(\mathrm{P}=0.052)$. Total chla mainly followed the trend of diatom chla, which mostly contributed to the total primary productivity. In detail, total chla and diatom chla slowly decreased during the lentification phase; they were zero during the first days of the rewetting (from RT1 to RT3); afterwards they showed a steep increase starting from RT5 (Fig. $1 \mathrm{a}, \mathrm{b}$ ). On the contrary, we observed a different pattern for cyanobacteria, which showed an in- crease during the lentification process (Fig. 1c). Green algae showed an opposite trend in comparison to diatoms, and this group characterized the rewetting phase (Fig. 1d).

A clear pattern was noticeable in terms of relative proportions of chla of the three main benthic autotrophic groups, which changed during the different phases of the study (Fig. 1 e-g). Diatom chla resulted as the most representative component at UP site, both before and after the
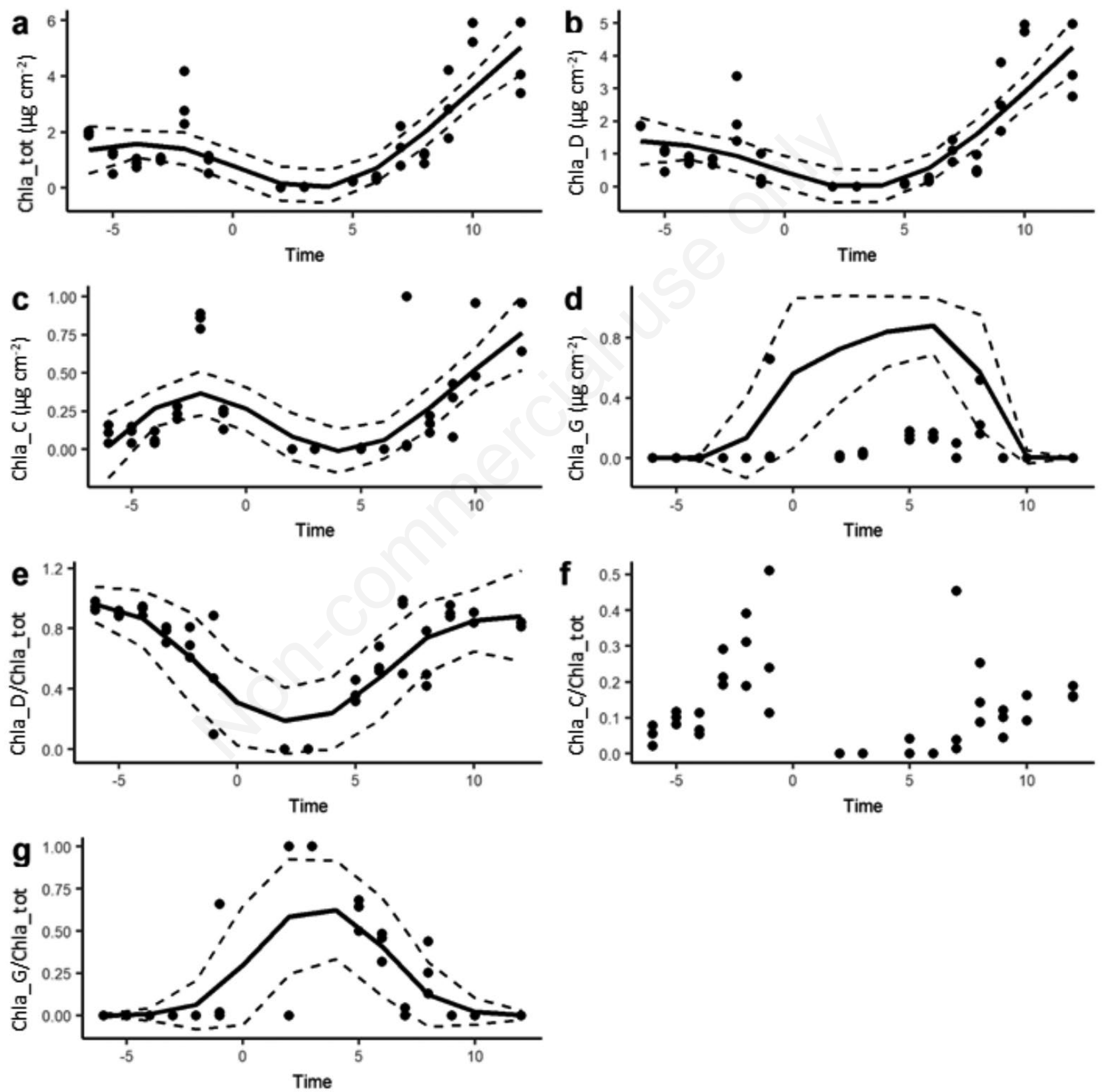

Fig. 1. Generalized Additive Models (GAMs) for (a) total chlorophyll $a$, (b) diatom chlorophyll $a$, (c) cyanobacteria chlorophyll $a$, (d) green algae chlorophyll $a$, (e) relative proportion of diatoms (diatom chlorophyll $a$ / total chlorophyll $a$ ), (f) relative proportion of cyanobacteria (cyanobacteria chlorophyll $a$ / total chlorophyll $a$ ), (g) relative proportion of green algae (green algae chlorophyll $a$ / total chlorophyll $a$ ). Black lines represent the predicted values of the models, while the dashed lines represent $95 \%$ confidence interval. 
drought. Under these conditions, the relative contribution of diatoms to the total chla ranged from $60 \%$ up to $100 \%$. Cyanobacteria at UP rapidly increased with the lentification progression and their relative contribution ranged from 30 to $41 \%$. The relative proportion of diatom chla at DW reached its lowest value during August 2017, when diatoms represented $47 \%$ of the total chla in the biofilm. DW tiles were bare from algal colonization during the first 7 days after water return. Afterwards, tiles were mainly dominated by green algae (RT3-RT4). Later, relative proportions changed again, with increasing values for diatom chla (RT5RT8). About 40 days after water return (RT9), the relative proportion of diatom chla reached values similar to those found at UP site (87-95\% of relative contribution to the total chla). GAMs statistically confirmed these trends for diatom and green algae relative proportions (Tab. 3 and Fig. 1).

\section{Diatom community}

During the survey we identified a total of 161 diatom species (Supplementary Material 2). The ordination performed with the PCoA clearly depicts three different groups of samples (Fig. 2). GROUP1 included: i) the samples collected during the stable phase, both in UP and DW sites, from March to June 2017 and ii) samples collected at UP sites during the rewetting phase. GROUP2 included sam- ples collected at both stations during lentification 2017 (July and August 2017). GROUP3 included all samples collected at DW site during the rewetting phase (JanuaryMarch 2018). The three groups can thus be considered as a proxy of the responses to hydrological disturbance, with GROUP1 representing the most stable hydrological conditions, GROUP2 the intermediate disturbance (water still persists, even if with almost null flow), GROUP3 including the most unstable conditions, with communities recovering after 5 months of drought. PERMANOVA showed significant differences among the three groups $(\mathrm{F}=12.19$; $\mathrm{P}=0.0001)$ and the post-hoc test confirmed differences among all groups (GROUP1 vs GROUP2 $\mathrm{F}=5.154$, $\mathrm{P}=0.0027$; GROUP1 vs GROUP3 $\mathrm{F}=18.340, \mathrm{P}=0.0003$; GROUP2 vs GROUP3 F=9.383, $\mathrm{P}=0.0003$ ).

Based on the three groups highlighted by the PCoA, we performed an Indicator Species Analysis to detect significant diatom species related to the three different hydrological conditions. Significant results of the ISA are shown in Tab. 4. We did not detect statistically significant species for GROUP 1 (stable conditions). On the contrary, GROUP 2 and 3 were characterized by species mainly belonging to the genera Navicula and Nitzschia (see Tab. 4 for details).

ANOVA detected significant differences among the three groups derived from the PCoA in terms of ecological guilds, life forms and eco-morphological groups (Tab. 5).

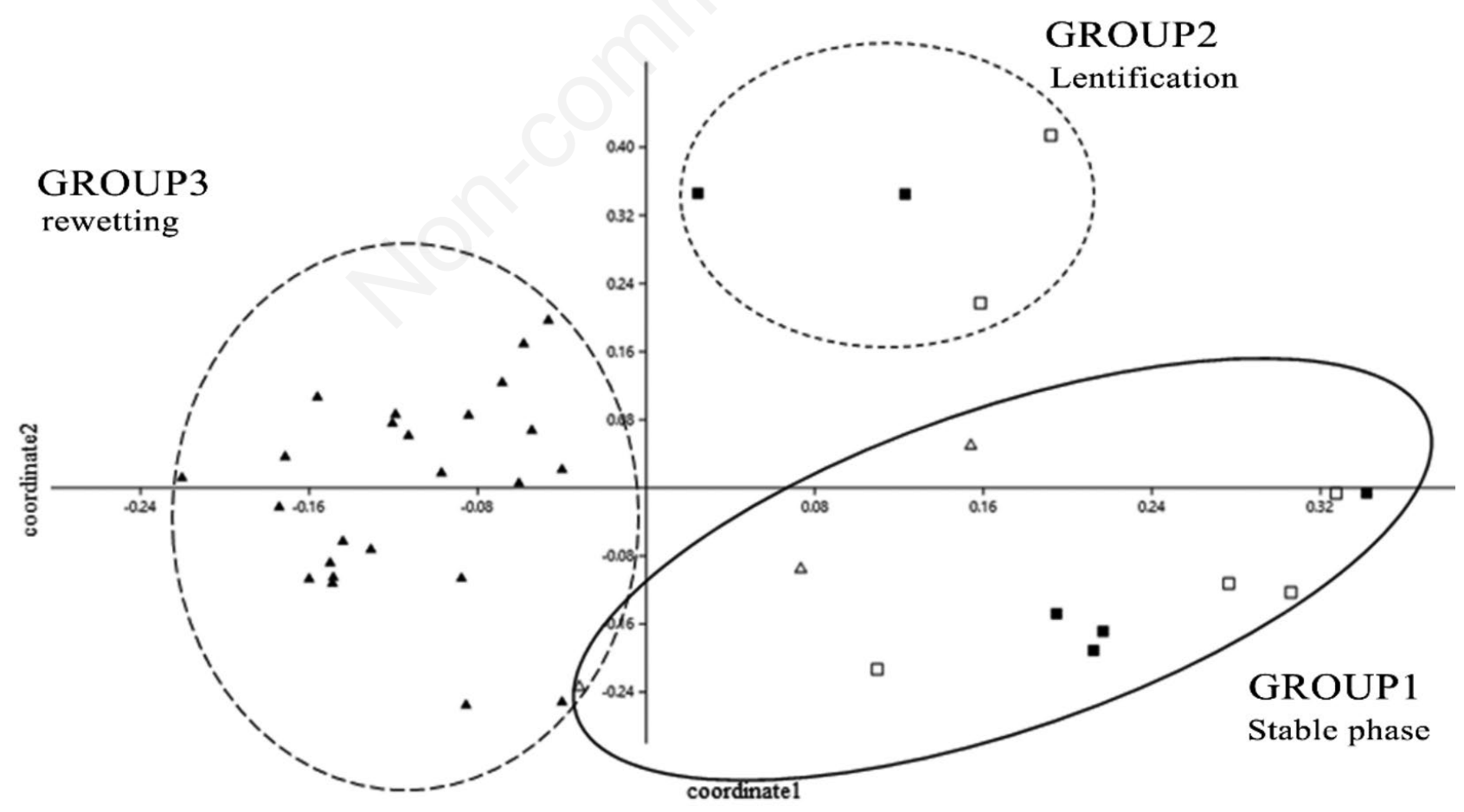

Fig. 2. Graphical result of the PCoA. Squares represent the samples collected during the pre-drought phases at upstream (unfilled squares) and downstream (filled squares) sites. Triangles represent samples collected during the rewetting at upstream (unfilled triangles) and downstream (filled triangles) sites. 
The low profile guild was significantly more abundant in the most stable conditions (GROUP 1), and its relative proportion significantly decreased both during the lentification (GROUP 2) and especially in the rewetting (GROUP 3), in which they presented the lowest abundances. The opposite pattern was observed for motile taxa, which presented the highest percentages during the rewetting phase. High profile taxa seemed to be affected more by the lentification process (stage at which they reached the minimum percentages), than by the rewetting. Concerning life-forms, we found significant results only for stalked and motile taxa. The relative proportion of stalked species steeply decreased over the time, showing the highest values during the stable periods and the lowest during the rewetting phase. Motile group was the most representative one during the rewetting phase.

Regarding the eco-morphological groups, the response of the LS2 group was strictly linked to Achnanthidium pyrenaicum (Hustedt) Kobayasi pattern, which was the main representative of this category and significantly more abundant under the stable conditions (GROUP1). Reimeria sinuata (Gregory) Kociolek \& Stoermer and Psammothidium bioretii (Germain) Bukhtiyarova et Round characterized LS3 group, whose abundance was greater during rewetting (GROUP3). The small high profile species (HS2, such as Encyonema ventricosum (Kütz- ing) Grunow and Fragilaria sp.) presented significant different percentages between GROUP2 and GROUP3, being more abundant in the rewetting phase. The group HS3 was significantly more abundant in the rewetting phase: Encyonema silesiacum (Bleisch) Mann and Gomphonema elegantissimum Reichardt \& Lange-Bertalot were noteworthy in this group and seemed to easily recover after the long drought. The motile eco-morphological groups represented by the smallest taxa (MS1; such as Fistulifera saprophila (Lange-Bertalot \& Bonik) Lange-Bertalot) and the intermediate-sized species (MS3; such as Nitzschia fonticola Grunow and Navicula antonii Lange-Bertalot) presented statistically significant pattern, being characteristic during the rewetting phase.

Results of the PRC analysis (Fig. 3) showed significant differences among treatments during the experiment $(\mathrm{F}=71.576 ; \mathrm{P}=0.001)$. Time and treatment explained the $84.2 \%$ of the total variance $($ Time $=39.8 \%$; Treatment $=$ $44.4 \%$ ). The taxon mostly contributing to the control samples (UP), was A. pyrenaicum, which represented more than $60 \%$ of the community during the whole survey. Similar patterns were observed for A. pyrenaicum (teratological form), Fragilaria vaucheriae (Kützing) Petersen and Diatoma ehrenbergii Kützing. The species with the highest affinity for recolonization conditions at DW site were F. saprophila, E. silesiacum, Achnanthidium

Tab. 4. Statistically significant indicator species, characterizing two of the three phases of the hydrological cycle (i.e., lentification and rewetting), obtained with the ISA.

\begin{tabular}{|c|c|c|}
\hline \multicolumn{3}{|c|}{ GROUP 2 lentification } \\
\hline Taxa & IndVal & $\mathbf{P}$ \\
\hline Cocconeis euglypta Ehrenberg & 0.897 & $0.002 * *$ \\
\hline Navicula capitatoradiata Germain & 0.96 & $0.001 * * *$ \\
\hline Navicula caterva Hohn \& Hellerman & 0.666 & $0.015^{*}$ \\
\hline Navicula cryptocephala Kützing & 0.778 & $0.005 * *$ \\
\hline Navicula splendicula Van Landingham & 0.672 & $0.012 *$ \\
\hline Nitzschia acicularis (Kützing) Smith & 0.642 & $0.041 *$ \\
\hline Nitzschia archibaldii Lange-Bertalot & 0.963 & $0.001 * * *$ \\
\hline Nitzschia palea (Kützing) W. Smith & 1.000 & $0.001 * * *$ \\
\hline Nitzschia palea var. debilis (Kützing) Grunow & 0.931 & $0.001 * * *$ \\
\hline Nitzschia paleacea (Grunow) Grunow & 0.856 & $0.001 * * *$ \\
\hline Nitzschia sp. (abnormal form) & 0.707 & $0.018 *$ \\
\hline Ulnaria acus (Kützing) Aboal & 0.635 & $0.027 *$ \\
\hline Ulnaria ulna (Nitzsch) Compère & 0.800 & $0.009 * *$ \\
\hline \multicolumn{3}{|c|}{ GROUP 3 rewetting } \\
\hline Taxa & IndVal & $\mathbf{P}$ \\
\hline Adlafia minuscula (Grunow) Lange-Bertalot & 0.775 & $0.004 * *$ \\
\hline Navicula reichardtiana Lange-Bertalot & 0.701 & $0.034 *$ \\
\hline Nitzschia costei Tudesque et al. & 0.683 & $0.047 *$ \\
\hline Nitzschia pusilla (Kützing) Grunow & 0.683 & $0.044 *$ \\
\hline Psammothidium bioretii (Germain) Bukhtiyarova et Round & 0.730 & $0.022 *$ \\
\hline
\end{tabular}


minutissimum (Kützing) Czarnecki and $R$. sinuata. When examining the temporal pattern of community composition, we could notice that the relative abundances of species at DW (RT4) were initially similar to those observed in the upstream site. However, as already pointed out, diatom density characterizing DW samples at RT4 was very scarce affecting the reliability of results deriving from their analysis. In the first phase of the colonization (RT5 and RT6) the early colonizers such as A. minutissimum, A. pyrenaicum and E. silesiacum, obtained a numerical advantage over subsequent immigrants thanks to their high reproductive rates. Despite this, and even if A. pyrenaicum significantly dominated the upstream section, it was not noteworthy at DW. Beside these three species, it is important to highlight the presence of $N$. fonticola already during this first stage of the colonization. As pointed out in Fig. 3, the distance between the reference line of the control and the treatments increased from RT5 to RT10, highlighting differences among UP and DW com- munities. During this time span we noticed at the DW site, a gradual decrease in the relative abundance of $A$. pyrenaicum and Cocconeis lineata Ehrenberg. At the same time, we observed an increase of E. silesiacum and Fragilaria sp., as well as an increase of species adapted to the physical disturbance, such as $N$. fonticola, and $F$. saprophila (accounting together more than $30 \%$ of the downstream communities). Almost at the end of the experiment (RT11 and RT12) reference and treatment lines got closer (Fig. 3), reflecting the resemblance of the communities inhabiting UP and DW sections.

\section{DISCUSSION}

The results obtained in the present paper showed that most of the environmental and chemical differences detected during the monitoring reflected in the best way the hydrological changes observed during the whole survey

Tab. 5. Results of the analysis of the variance (ANOVA) performed to detect significant differences among the three groups derived from the PCoA, in terms of ecological guils, life forms and eco-morphological functional groups. Significant results are shown in bold.

\begin{tabular}{|c|c|c|c|c|c|c|}
\hline & & \multicolumn{2}{|c|}{$\begin{array}{l}\text { Hydrological disturbance } \\
\text { (GROUP 1, 2, 3) }\end{array}$} & \multicolumn{3}{|c|}{ Tukey's post-hoc comparisons } \\
\hline & & $\mathbf{F}$ & $\mathbf{P}$ & GROUP 1 vs & GROUP 1 vs & GROUP 2 vs \\
\hline & & & & GROUP 2 & GROUP 3 & GROUP 3 \\
\hline \multirow[t]{4}{*}{ Ecological guilds } & Low profile & 19.090 & $<0.001$ & 0.0001 & 0.0002 & 0.7068 \\
\hline & High profile & 7.138 & 0.003 & 0.0960 & 0.2570 & 0.0020 \\
\hline & Motile & 5.099 & 0.012 & 0.5370 & 0.0100 & 0.1140 \\
\hline & Planktonic & 0.786 & 0.465 & 0.5960 & 0.9800 & 0.4800 \\
\hline \multirow[t]{5}{*}{ Life forms } & Adnate & 1.226 & 0.309 & 0.2821 & 0.8103 & 0.6237 \\
\hline & Pad attached & 1.188 & 0.3204 & 0.9287 & 0.5147 & 0.3162 \\
\hline & Stalked & 19.15 & $<0.001$ & 0.0001 & 0.0002 & 0.6797 \\
\hline & Mobile & 5.792 & 0.008 & 0.4877 & 0.0066 & 0.0908 \\
\hline & Tube forming & 0.511 & 0.606 & 0.5919 & 0.7735 & 0.9519 \\
\hline \multirow[t]{15}{*}{ Eco-morphological groups } & LS1 & 2.273 & 0.1205 & 0.2278 & 0.9549 & 0.1362 \\
\hline & LS2 & 24.35 & $<0.001$ & 0.0001 & 0.0001 & 0.9658 \\
\hline & LS3 & 5.797 & 0.007 & 0.8822 & 0.0310 & 0.0099 \\
\hline & LS4 & 1.265 & 0.297 & 0.9179 & 0.2909 & 0.4997 \\
\hline & LS5 & 1.808 & 0.1813 & 0.2012 & 0.3016 & 0.9665 \\
\hline & HS1 & 0.4685 & 0.6304 & 0.9681 & 0.7712 & 0.6241 \\
\hline & HS2 & 5.348 & 0.01032 & 0.0875 & 0.5857 & 0.0090 \\
\hline & HS3 & 14.67 & $<0.001$ & 0.0216 & 0.0390 & 0.0001 \\
\hline & HS4 * & $\mathrm{U}=50.5$ & 0.529 & - & - & - \\
\hline & HS5 & 0.3171 & 0.7307 & 0.9389 & 0.8928 & 0.7099 \\
\hline & MS1 & 8.327 & 0.001 & 0.9952 & 0.0043 & 0.0034 \\
\hline & MS2 & 1.531 & 0.2327 & 0.2286 & 0.9063 & 0.4291 \\
\hline & MS3 & 8.589 & 0.001 & 0.9924 & 0.0029 & 0.0039 \\
\hline & MS4 & 1.425 & 0.2563 & 0.2263 & 0.6846 & 0.6735 \\
\hline & MS5 & 0.2253 & 0.7996 & 0.8322 & 0.8301 & 1.0000 \\
\hline
\end{tabular}


(Supplementary Material 3). The three phases of the hydrological cycle of the Pellice river (i.e., stable conditions, lentification and rewetting) were significantly characterized by different levels of productivity and changes in the diatom community, both from the taxonomic and the functional points of view (Supplementary Material 3).

In the following sections we will highlight the main results obtained in terms of algal response to the different hydrological phases.

\section{Dynamics of the benthic autotrophic communities before and after the drought}

The relative proportion of chlorophyll $a$ for the three main autotrophic periphyton groups resulted in a reliable metric for the evaluation of the hydrological disturbance, as the three groups showed clearly diverse patterns and responses during the different phases of the experiment, as highlighted by recent studies (Piano et al., 2017; Zlatanović et al., 2018). Under stable conditions, diatoms always accounted for more than $60 \%$ of the total chlorophyll $a$, but they decreased with the lentification, being replaced by cyanobacteria, especially at DW site where the disturbance was higher. After water return, we detected no algal activity during the first three sampling campaigns (T1-T3). Afterwards, green algae were the only representative group of the biofilm and their dominance lasted for one month after the water return, with a maximum absolute value of chlorophyll $a$ of $1.12 \mu \mathrm{g} \mathrm{cm}^{-2}$. Their post-drought colonization could have been favoured by the presence of moist habitats disconnected from the main flow. Starting from RT9 (38 days after water return), the relative proportions of the three main autotrophic groups reached again the values observed at the upstream section. Therefore, diatoms proved to be the group most negatively influenced by both lentification and rewetting. Cyanobacteria were favoured by the lentification process, when the formation of shallow pools and high water temperature likely created the optimum environmental conditions for their growth (Romaní et al., 2012). Green algae seemed to take advantage from the drought, and, as already observed by other authors, showed an opposite trend with diatoms (Luttenton and Lowe, 2006; Piano et al., 2015).

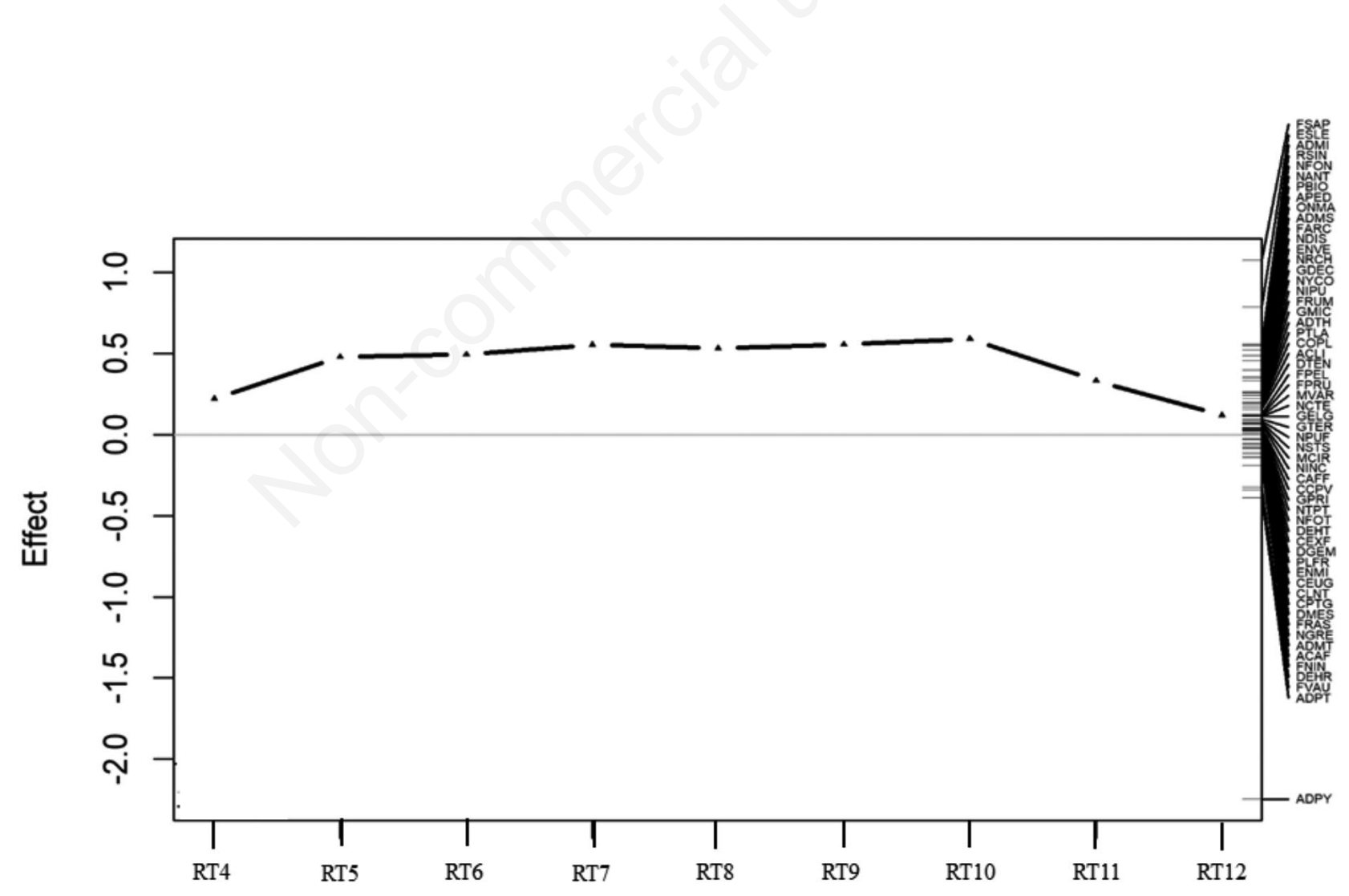

\section{Sampling occasions}

Fig. 3. Principal response curve (PRC) diagram showing the temporal pattern of diatom community during the rewetting phase. The horizontal grey line represents the community composition of the reference site (UP), while the black line represents the pattern of diatom recovery in the intermittent site. For diatom codes displayed in the right part of the graph see Supplementary Material 2. 


\section{Responses of the diatom community}

Visual inspection of the PCoA ordination depicts a clear difference in terms of taxonomic composition among samples, allowing us to identify three hydrological phases. The stable phase was mainly characterized by $A$. pyrenaicum and A. minutissimum, which are two of the most representative species inhabiting the Alpine watercourses of the NW-Italy, adapted to live in fast-flowing waters, with low nutrient content (Falasco et al., 2013). During the lentification phase, we observed an increase of two representatives of the genus Nitzschia: N. archibaldii and N. fonticola (more detailed results concerning the changes within the diatom community during the lentification phase are presented in Falasco et al., 2018b). As already observed in previous studies, these motile taxa present a competitive advantage if compared to sessile diatoms, because, through their movement across the substrate, they can find and exploit more suitable habitats (Falasco et al., 2018b). During rewetting, communities rapidly changed, displaying different relative abundances. Principal Response Curve analysis showed a complete recovery of the downstream community at the end of the experiment, 73 days after water return. The time of recovery generally depends from several factors, such as species composition before the disturbance event and that of the upstream sections, the presence of refugia, the velocity of the water retreat and so on. As we will discuss in the following section, the short distance between upstream and downstream sites certainly favoured the recolonization once water connectivity was restored, and upstream site represented the only source of propagules for the community recovery. In a previous study carried out in the Mediterranean area (Falasco et al., 2018a), we found that communities composed of sensitive species, such as threatened taxa, recovered slower (more than 90 days) than assemblages composed of ubiquitous and generalist species (ca. 30 days). In the present study, most of the species detected at the upstream site were able to drift and start the colonization on downstream cobbles, already 14 days after water return. However, results obtained through the PRC showed that a good recovery of the downstream community took as long as two months after water return. This result, once more, underlined the low adaptation capacity of the diatom Alpine communities to cope with droughts, in comparison to the Mediterranean ones, which are naturally adapted to this kind of events.

In our study, among the three resilience mechanisms presented by Van Looy et al. (2019), habitat connectivity and competition for resources proved to be the main resilience mechanisms driving diatom recolonization process. Indeed, diatoms had no possibility to exploit refugia, since no residual pools lasted during the drought phase and no dry biofilm was present on our artificial substrates. Therefore, colonization was exclusively driven by the drift from the upstream section. In a first phase of the rewetting, pri- ority effect and monopolization certainly dominated (De Meester et al., 2016), with ruderal species prevailing over secondary colonizers thanks to their high reproductive rates. In a second step, the competition for the resources became an important factor in shaping diatom community at different levels and species adapted to physical disturbance were favoured. At the end of the experiment, community compositions of the sites were almost similar. During the recolonization process we cannot exclude the role of the competition exerted by the other autotrophic groups growing within the biofilm (especially green algae) in shaping the diatom communities of the recovery phase. Moreover, also the pressure exerted by the scrapers had certainly contributed to shape the diatom community during the whole experiment (Piano et al., 2019b) and probably limited the growth of stalked taxa, more subject to herbivory pressure than other guilds (Passy and Larson, 2019), especially during the rewetting phase.

When considering the response of functional traits, we expected that generalist, small low profile taxa, tolerating physical disturbance and with high reproductive rates, would have characterized the first phase of the recolonization. Our results partially confirmed this hypothesis which was in accordance with previous findings (B-Béres et al., 2019). However, high profile and motile groups rapidly increased their abundance disadvantaging first colonizers at the downstream site (Supplementary Material 3). Pioneer species are able to cope with physical disturbance and probably exploited detritus as substratum, contributing to the formation of a basal layer. Stalked taxa resulted the most disadvantaged group, decreasing their abundance in summer and slowly recovering during the rewetting. Beside the control exerted by scrapers on this group, we can hypothesise that the stalks produced by these cells expose the individuals to the desiccation occurred during the low discharge. Our results confirmed the observations of Elias et al. (2015), who found a significant decrease of stalked taxa still one year after water return.

\section{CONCLUSIONS}

Diatoms proved again to be one of the most sensitive group to hydrological disturbance and to be scarcely resistant to drought. As demonstrated by the chlorophyll $a$ pattern, diatoms are rapidly replaced by other benthic groups, which better cope with lentification and desiccation. Despite their high resilience capability, the complete recovery of the diatom community occurred 73 days after water return.

Even if in a recent paper we pointed out that diatom community likely does not possess a "drying memory" of summer droughts (Piano et al., 2019a), our results suggest that these organisms can be significantly affected by the occurrence of a supraseasonal drought, from both structural 
and compositional points of views. Intermittency in the Alpine area is quite a recent phenomenon, but considering the worsening of water scarcity scenario, the inclusion of the benthic chlorophyll $a$ and functional group analyses should be carefully taken into consideration for the hydrological disturbance assessment (Falasco et al., 2016b).

\section{ACKNOWLEDGMENTS}

This study was carried out as part of the activities of ALPSTREAM, a research center financed by FESR, Interreg Alcotra 2014-2020, EcO Project of the Piter Terres Monviso.

This work is part of the research fellowship "Risposte strutturali e funzionali delle comunità di diatomee bentoniche in fiumi alpini soggetti ad intermittenza idrologica" won at UNIUPO by Dr. Falasco and funded by the Italian Ministry of Research (MIUR) in the framework of the Research Project of National Interest (PRIN) "NO ACQUA”, Grant No. 201572HW8F. We thank Daniele Morandini for his support during the sampling campaigns.

\section{REFERENCES}

Acuña V, Casellas M, Corcoll N, Timoner X, Sabater S, 2015. Increasing extent of periods of no flow in intermittent waterways promotes heterotrophy. Freshwater Biol. 60:18101823.

APAT-IRSA CNR, 2003. [Metodi analitici per le acque, vol I. Rapporti 29/2003].[Report in Italian]. APAT, Rome.

B-Béres V, Lukács Á, Török P, Kókai Z, Novák Z, T-Krasznai E, Tóthmérész B, Bácsi I, 2016. Combined eco-morphological functional groups are reliable indicators of colonisation processes of benthic diatom assemblages in a lowland stream. Ecol. Indic. 64:31-38.

B-Béres V, Tóthmérész B, Bácsi I, Borics G, Abonyi A, Tapolczai K, Rimet F, Bouchez A, Várbíró G, Török P, 2019. Autumn drought drives functional diversity of benthic diatom assemblages of continental streams. Adv. Water Resour. 126:129-136.

De Caceres M, Legendre P, 2009. Associations between species and groups of sites: indices and statistical inference. Ecology, URL http://sites.google.com/site/miqueldecaceres/

De Meester L, Vanoverbeke J, Kilsdonk LJ, Urban MC, 2016. Evolving perspectives on monopolization and priority effects. Trends Ecol. Evol. 31:136-146.

Doretto A, Piano E, Falasco E, Fenoglio S, Bruno MC, Bona F, 2018. Investigating the role of refuges and drift on the resilience of macroinvertebrate communities to drying conditions: An experiment in artificial streams. River Res. Appl. 34:777-785.

Doretto A, Bona F, Falasco E, Morandini D, Piano E, Fenoglio S, 2020. Stay with the flow: How macroinvertebrate communities recover during the rewetting phase in Alpine streams affected by an exceptional drought. River Res. Appl. 36:91-101.

Elias CL, Calapez AR, Almeida SFP, Feio MJ, 2015. From perennial to temporary streams: an extreme drought as a driving force of freshwater communities' traits. Mar. Freshwater Res. 66:469-480.

European Committee for Standardization, 2003. Water Quality Guidance Standard for the Routine Sampling and Pretreatment of Benthic Diatoms from Rivers. European Standard EN 13946. Brussels, European Committee for Standardization: $14 \mathrm{pp}$.

Falasco E, Piano E, Bona F, 2013. [Guida al riconoscimento e all'ecologia delle principali diatomee fluviali dell'Italia nord occidentale].[Book in Italian]. Centro italiano studi di biologia ambientale, Reggio Emilia: 292 pp.

Falasco E, Bona F, Isaia M, Piano E, Wetzel CE, Hoffmann L, Ector L, 2015. Nupela troglophila sp. nov., an aerophilous diatom (Bacillariophyta) from the Bossea cave (NW Italy), with notes on its ecology. Fottea 15:1-9.

Falasco E, Piano E, Bona F, 2016a. Diatom flora in Mediterranean streams: flow intermittency threatens endangered species. Biodivers. Conserv. 25:2965-2986.

Falasco E, Piano E, Bona F, 2016b. Suggestions for diatombased monitoring in intermittent streams. Knowl. Manag. Aquat. Ecosyst. 417:38.

Falasco E, Piano E, Doretto A, Fenoglio S, Bona F, 2018a. Resilience of benthic diatom communities in Mediterranean streams: the role of endangered species. Mar. Freshwater Res. 70:212-224.

Falasco E, Piano E, Doretto A, Fenoglio S, Bona F, 2018 b. Lentification in Alpine rivers: patterns of diatom assemblages and functional traits. Aquat. Sci. 80:36-46.

Fenoglio S, Bo T, Cucco M, Malacarne G, 2007. Response of benthic invertebrate assemblages to varying drought conditions in the Po river (NW Italy). Ital. J. Zool. 74:191-201.

Fenoglio S, Bo T, Cucco M, Mercalli L, Malacarne G, 2010. Effects of global climate change on freshwater biota: a review with special emphasis on the Italian situation. Ital. J. Zool. 77:374-383.

Hammer Ø, Harper DAT, Ryan PD, 2001. PAST: Paleontological Statistics software package for education and data analysis. Paleontologia Electronica 4:1-9.

Kahlert M, McKie BG, 2014. Comparing new and conventional methods to estimate benthic algal biomass and composition in freshwaters. Environ. Sci-Proc. Imp. 16:2627-2634.

Lake PS, 2003. Ecological effects of perturbation by drought in flowing waters. Freshwater Biol. 48:1161-1172.

Luttenton MR, Lowe RL, 2006. Response of a lentic periphyton community to nutrient enrichment at low P:N ratios. J. Phycol. 42:1007-1015.

McQuoid MR, Hobson LA, 1996. Diatom resting stages. J. Phycol. 32:889-902.

Oksanen J, Blanchet FG, Friendly M, Kindt R, Legendre P, McGlinn D, Minchin PR, O'Hara RB, Simpson GL, Solymos P, Stevens MHH, Szoecs E, Wagner H, 2019. vegan: Community Ecology Package. R package version 2.5-4. Available from: https://CRAN.R-project.org/package=vegan

Passy SI, 2007. Diatom ecological guilds display distinct and predictable behavior along nutrient and disturbance gradients in running waters. Aquat. Bot. 86 171-178.

Passy SI, Larson CA, 2019. Niche dimensionality and herbivory control stream algal biomass via shifts in guild composition, richness, and evenness. Ecology 100:e02831. 
Piano E, Bona F, Falasco E, La Morgia V, Badino G, Isaia M, 2015. Environmental drivers of phototrophic biofilms in an Alpine show cave (SW-Italian Alps). Sci. Total Environ. 536:1007-1018.

Piano E, Falasco E, Bona F, 2017. Mediterranean rivers: consequences of water scarcity on benthic algal chlorophyll $a$ content. J. Limnol. 76:39-48. doi: 10.4081/jlimnol.2016. 1503.

Piano E, Doretto A, Falasco E, Fenoglio S, Gruppuso L, Nizzoli D, Viaroli P, Bona F, 2019a. If Alpine streams run dry: the drought memory of benthic communities. Aquat. Sci. 81:32.

Piano E, Doretto A, Falasco E, Gruppuso L, Fenoglio S, Bona F, 2019b. The role of recurrent dewatering events in shaping ecological niches of scrapers in intermittent Alpine streams. Hydrobiologia 841:177-189.

Rimet F, Bouchez A, 2012. Life-forms, cell-sizes and ecological guilds of diatoms in European rivers. Knowl. Manag. Aquat. Ecosyst. 406:01.

Romaní AM, Amalfitano S, Artigas J, Fazi S, Sabater S, Timoner X, Ylla I, Zoppini A, 2012. Microbial biofilm structure and organic matter use in Mediterranean streams. Hydrobiologia 719:43-58.

Robson BJ, Matthews TG, 2004. Drought refuges affect algal recolonization in intermittent streams. River. Res. Applic. 20:753-763.

Sabater S, 2008. Alterations of the global water cycle and their effects on river structure, function and services. Freshw. Rev. 1:75-88.

Soininen J, Jamoneau A, Rosebery J, Passy SI, 2016. Global patterns and drivers of species and trait composition in diatoms. Global Ecol. Biogeogr. 25:940-950.
Souffreau C, Vanormelingen P, Sabbe K, Vyverman W, 2013. Tolerance of resting cells of freshwater and terrestrial benthic diatoms to experimental desiccation and freezing is habitat-dependent. Phycologia 52:246-255.

Stanley EH, Fisher SG, Jones JB Jr, 2004. Effects of water loss on primary production: a landscape-scale model. Aquat. Sci. 66:130-138

Timoner X, Borrego CM, Acuña V, Sabater S, 2014. The dynamics of biofilm bacterial communities is driven by flow wax and wane in a temporary stream. Limnol. Oceanogr. 59:2057-2067.

van den Brink PJ, Den Besten PJ, bij de Vaate A, ter Braak CJ, 2009. Principal response curves technique for the analysis of multivariate biomonitoring time series. Environ. Monit. Assess. 152:271-281.

Van Looy K, Tonkin JD, Floury M, Leigh C, Soininen J, Larsen S, Datry, T, Heino J, LeRoy N, M Delong, Jähnig SC, Datry T, Bonada N, Rosebery J, Jamoneau A, Ormerod SJ, Collier KJ, Wolter K, 2019. The three Rs of river ecosystem resilience: Resources, recruitment, and refugia. River Res. Appl. 35:107-120.

Wood S, Wood MS, 2015. Package 'mgev'. R package ver. 1-7.

Zlatanović S, Fabian J, Premke K, Mutz M, 2018. Shading and sediment structure effects on stream metabolism resistance and resilience to infrequent droughts. Sci. Total Enniron. 621:1233-1242.

Zuur AF, Ieno EN, Walker NJ, Savaliev AA, Smith GM, 2009. Mixed effect models and extensions in ecology with R. Springer: 600 pp.

Zuur AF, Ieno EN, Elphick CS, 2010. A protocol for data exploration to avoid common statistical problems. Methods Ecol. Evol. 1:3-14. 